\title{
Central Nervous System Infections Due to Aspergillus and Other Hyaline Molds
}

\author{
Marisa H. Miceli \\ Division of Infectious Diseases, University of Michigan Health System, Ann Arbor, MI 48109, USA; \\ mmiceli@med.umich.edu
}

Received: 28 June 2019; Accepted: 27 August 2019; Published: 30 August 2019

\begin{abstract}
Central nervous system infections due to Aspergillus spp and other hyaline molds such as Fusarium and Scedosporium spp are rare but fatal conditions. Invasion of the central nervous system (CNS) tends to occur as a result of hematogenous dissemination among immunocompromised patients, and by local extension or direct inoculation secondary to trauma in immunocompetent hosts. Efforts should be directed to confirm the diagnosis by image-guided stereotactic brain biopsy when feasible. Non-culture methods could be useful to support the diagnosis, but they have not been validated to be performed in cerebral spinal fluid. Treatment of these infections is challenging given the variable susceptibility profile of these pathogens and the penetration of antifungal agents into the brain.
\end{abstract}

Keywords: central nervous system; Aspergillus; hyaline molds

\section{Introduction}

Invasive mold infections are a cause of increased morbidity and mortality among immunosuppressed patients [1]. In particular, fungal infections of the central nervous system (CNS) usually have devastating consequences. This is due in part to their often-non-specific presentation, delayed diagnosis, and limited treatment options. Typically, neurosurgical procedures are not a therapeutic option due to the severity of patients' underlying conditions and profound thrombocytopenia. This article presents an overview of the epidemiology, clinical presentation, diagnosis, and treatment of CNS infections due to Aspergillus and other hyaline molds.

\section{Aspergillus Species}

Invasive aspergillosis is the most common invasive mold infection, particularly among hematological cancer patients and peripheral stem cell transplant recipients [1]. Aspergillus fumigatus accounts for almost $90 \%$ of the infections in humans. Other non-fumigatus Aspergillus spp, including A. flavus, A. terreus, A. niger, A.nidulans, A. ustus, and oryzae are emerging as causes of infection. A high prevalence of non-fumigatus Aspergillus spp has been reported in tropical and subtropical geographic areas including Southeast Asia, the Middle East, and North America [2,3]. Most infections of the CNS in immunosuppressed hosts are due to Aspergillus fumigatus, while A. flavus is the predominant species among immunocompetent individuals [4]. However, infection due to other, less common species with intrinsic resistance to commonly used antifungal agents, may occur regardless of immune status.

\subsection{Pathogenesis}

Neuroaspergillosis may occur by hematogenous dissemination in the setting of disseminated infection, or by direct extension from the ear, paranasal sinuses, or mastoids in patients with localized invasive aspergillosis [4]. Hematogenous dissemination from invasive lung infection is more common among immunocompromised patients, while extension from sinusitis, mastoiditis, 
and direct penetration of the mold into the brain secondary to cranial trauma, injury, or neurosurgery are more commonly seen in immunocompetent hosts [4-7].

The intrinsic mechanisms by which Aspergillus spp penetrate the blood-brain barrier and produce damage of the central nervous system continue to be the subject of ongoing research. Studies have shown that Aspergillus spp produce mycotoxins (including aflatoxins and gliotoxins) that inhibit phagocytosis and reduce opsonization of the conidia during invasion [8-11]. Micotoxins have the ability to alter the integrity of the blood-brain barrier and damage and kill neurons, astrocytes and microglia [12]. In patients with profound immunosuppression, Aspergillus angioinvasion of the brain may result in cerebral infarction, hemorrhage, mycotic aneurysm, and meningitis [13]. Patients with a preserved immune system may be able to develop granulomas, brain abscesses and meningitis [14].

\subsection{Clinical Presentation and Outcome}

Clinical presentation of Aspergillus infection of the CNS is non-specific and varies depending on the extension of the infection. Indeed, Aspergillus invasion of the CNS may result in brain abscess, cerebritis, meningitis, cranial sinus thromboses, and ventriculitis. Therefore, patients may present with a variety of signs and symptoms, such as fevers, headaches, lethargy, altered mental status, seizures, abnormal gait, dizziness, or focal neurological findings [15]. Overall, the prognosis of patients with cerebral aspergillosis is poor. A recent study showed a median survival of 3.5 months after the diagnosis of CNS invasive mold infections, including aspergillosis, among patients with hematological malignancies [4]. In this study, mortality rate for mold infection as the primary cause of death was $33 \%$ (IFI CNS $29 \%$ vs. pulmonary IFI $46 \%, p=0.32$ ). Mortality from hematological malignancy disease with IFI as a contributory factor was $44 \%$. One-year mortality rate was significantly higher among patients with CNS fungal infections compared to those with a pulmonary infection as a contributory factor $(52 \%$ vs. $15 \%, p=0.026)$.

\subsection{Diagnosis}

Brain imaging is essential in the diagnosis, but there are not specific radiological findings for the neuroaspergillosis. Computed tomography (CT) and magnetic resonance imaging (MRI) of the brain with contrast are critical to evaluate patients with suspected CNS involvement $[16,17]$. Intracranial dural enhancement may occur secondary to direct extension from sinuses with mucosal thickening and bone erosion. Ring-enhancing lesions consistent with abscesses are not uncommon. Patients with CNS aspergillosis secondary to direct invasion from the sinuses develop single lesions within the frontal or temporal lobe, while patients with hematogenous dissemination may present single or multiple lesions at the gray-white junction. Cerebral cortical and subcortical infarction, with or without hemorrhagic transformation and mycotic aneurysms, typically develop as result of angioinvasion [14,18].

The yield of image-guided stereotactic brain biopsy for microbiological and pathological diagnosis of focal lesions is high (80-90\%), and it should be performed whenever possible [19]. Non-culture based methods for the diagnosis of invasive aspergillosis such as galactomannan (GM) and PCR have been only validated for their use in serum and bronchoalveolar lavage. 1,3-beta-di-glucan (BDG) has been validated and approved by the Food and Drug Administration for its use in serum only [20]. A positive test result of either of these biomarkers may support the diagnosis of CNS aspergillosis in the right setting. Off label testing of cerebral spinal fluid (CSF) with GM, BDG, or PCR could be helpful, particularly when performing brain biopsy is not an option. For instance, the detection of Aspergillus PCR, or a positive GM or BDG in the CSF of a patient suspected of cerebral aspergillosis, may support the diagnosis [21-25].

\subsection{Treatment}

Surgical excision of infected tissue such as paranasal sinuses, bone, and brain abscesses should be pursued when feasible [1]. A small retrospective study suggested that surgical resection of cerebral lesions in combination with antifungal therapy with voriconazole may improve survival [26]. 
For decades, the only therapeutic option for invasive aspergillosis was conventional amphotericin B (AmB). However, AmB compounds are large molecules and their CNS penetration is limited [27]. In addition, treatment is typically limited by renal and infusion related toxicities [28]. Liposomal formulations of AmB are associated with fewer toxicities and are usually better tolerated. Favorable responses of CNS aspergillosis in animal models and patients treated with lipid formulations of amphotericin B have been reported [29-31].

Of all available systemic antifungals, voriconazole achieves the widest distribution in the CSF, with CSF concentrations close to $50 \%$ of plasma concentration [27] (Table 1). Open-label studies of voriconazole vs. amphotericin B for the treatment of invasive aspergillosis showed a trend toward improvement of CNS aspergillosis among patients treated with voriconazole $[26,32,33]$.

Table 1. Antifungal agents and central nervous system penetration.

\begin{tabular}{|c|c|c|c|c|}
\hline Antifungal Agent & Molecular Mass & $\begin{array}{l}\text { Protein } \\
\text { Binding }\end{array}$ & $\begin{array}{c}\text { CSF } \\
\text { Concentration * }\end{array}$ & Comment \\
\hline Voriconazole & 349 Daltons & $58 \%$ & $\sim 50 \%$ & Small moderately lipophilic molecule \\
\hline Itraconazole & 705 Daltons & $99.8 \%$ & $<10 \%$ & Lipophilic compound \\
\hline $\begin{array}{l}\text { Amphotericin B } \\
\text { and lipid } \\
\text { formulations }\end{array}$ & 924 Daltons & $90 \%$ & $\begin{array}{l}\text { Poor in adults; } \\
40-90 \% \text { in neonates } \\
\text { Limited data with } \\
\text { lipid formulations }\end{array}$ & $\begin{array}{l}\text { Large molecule with a hydrophilic } \\
\text { polydroxyl chain and a lipophilic } \\
\text { polyene hydrocarbon chain, poorly } \\
\text { soluble in water }\end{array}$ \\
\hline
\end{tabular}

* percentage of plasma concentration, data from animal and human studies [27,34].

Current guidelines recommend the use of voriconazole (oral or IV) as a first line treatment of CNS aspergillosis [1,35]. Standard IV loading of voriconazole with $6 \mathrm{mg} / \mathrm{kg}$ every $12 \mathrm{~h}$ for two doses followed by $4 \mathrm{mg} / \mathrm{kg}$ Q12 h. Oral loading dose is $400 \mathrm{mg}$ Q12 h $\times 2$ doses, followed by $200 \mathrm{mg}$ PO q $12 \mathrm{~h}$. Duration of antifungal treatment is not clearly established and typically continues for several months, depending on the clinical and radiological response and ongoing immunosuppression.

Voriconazole toxicities are more common among patients with elevated drug concentrations in serum [36]. For instance, hepatotoxicity and peripheral and central neurologic symptoms and visual hallucinations are typically observed in patients with higher drug concentration levels [37]. Therapeutic drug monitoring is useful to optimize the efficacy and safety of voriconazole, particularly among patients receiving drugs that may affect voriconazole serum concentrations such as antiseizure medications (phenytoin, phenobarbital, others) [1,35].

Similar to AmB, itraconazole, and posaconazole are large molecules ( $>700$-dalton) and they exhibit limited penetration to the CNS (Table 1), but have been successfully used in patients who were refractory to, or intolerant of, conventional therapy with voriconazole [38-41].

Echinocandins are active against Aspergillus spp, but their use (alone or in combination) should be limited to salvage therapy. Biodistribution of echinocandins to the eye and uninfected CSF is low. Their use for CNS aspergillosis is not recommended. However, successful cases treated with caspofungin and micafungin have been reported [42,43].

European guidelines include isavuconazole as an option for the treatment of invasive aspergillosis, including cerebral aspergillosis [35]. Animal studies have demonstrated efficient penetration and homogeneous distribution patterns of isavuconazole in the infected brain [34]. In addition, there have been some reports of patients with CNS aspergillosis successfully treated with this drug $[44,45]$. 
In addition to antifungal therapy, immunosuppression should be reduced or reversed whenever possible [1]. Currently, there is no data to support the use of combination antifungal therapy for CNS aspergillosis, although some animal studies and case reports have shown favorable responses. Similarly, the use of corticosteroids and intrathecal antifungal therapy may be detrimental, and is not recommended $[1,46]$.

Figure 1 illustrates a case of proven cerebral aspergillosis in a liver transplant recipient, diagnosed on the bases of clinical presentation, MRI brain, and brain biopsy. Patient was treated with voriconazole and reduction of immunosuppression (mycophenolate). Antifungal therapy was continued beyond 12 months from diagnosis, with significant reduction of the size of the brain lesions.

Figure 1 -MRI findings in a patient with aspergillosis of the central nervous system
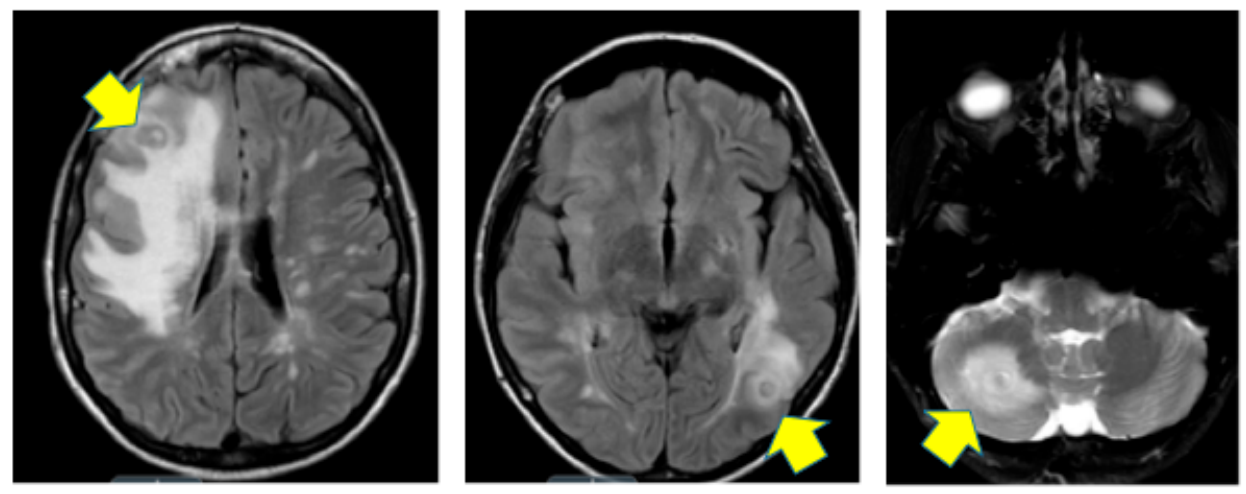

Figure 1. Proven cerebral aspergillosis in a 30-year old female diagnosed within 45 days after orthotopic liver transplantation. MR of the brain shows hyperintense T2 and FLAIR signal throughout the cerebral white matter, and deep gray nuclei structures with discrete ring enhancing lesions and surrounding edema seen in the left occipital lobe and right cerebellum (arrows).

\section{Other Hyaline Molds}

\subsection{Fusarium Species}

In recent years, there has been an increase in the number of invasive infections due to Fusarium spp in patients with underlying immunosuppression. Fusarium spp are the second most frequent cause of invasive mold infection in immunocompromised patients after Aspergillus spp [47-49]. Fusarium solani is the most frequent species causing invasive disease in patients with hematological malignancies, stem cell transplant recipients, and prolonged neutropenia [50-52]. Similar to Aspergillus spp, Fusarium spp has the ability to produce mycotoxins (trichothecenes and fumonisins); the main role of these virulence factors is suppression of humoral and cellular immunity. The most common mycotoxin produced by Fusarium spp is fumonisin B1, which has been associated with cerebral invasion, causing neural axon degeneration, and abnormal mitochondrial function [53]. Cerebral fusariosis is typically diagnosed in the setting of disseminated infection [54]. Patients may develop single or multiple brain abscesses, meningitis, endophthalmitis, chorioretinitis, cutaneous nodules, and fungemia [55]. The most common species include F. solani, F. oxysporum, and F. moliniforme complexes [47]. Similar to other invasive mold infections, definitive diagnosis is made by direct pathological exam and identification of the organism invading tissue (brain biopsy, CSF, vitreal fluid). Fusarium spp can cause fungemia and therefore, the diagnosis can sometimes be made on the basis of positive blood cultures [52]. Non-cultural methods such as GM and BDG in serum, BAL, and CSF are non-specific and could be positive in patients with invasive fusariosis [20].

Treatment of invasive fusariosis is challenging given the severity of this infection, variable antifungal susceptibility, and profound immunosuppression of the host. Typically, these patients start a combination of lipid formulation $\mathrm{AmB}$ and voriconazole, pending susceptibilities. 


\subsection{Scedosporium Species}

Most common Scedosporium species causing infection in humans include S. apoiospermum and S. proliferans (now Lomentospora prolificans). Most CNS infections due to S. apiospermum occur in immunocompetent patients, typically associated with near drowning, motor vehicle accidents, or direct inoculation (neurosurgery, CSF drainage devices, shunts, etc.) [56-58]. Cerebral scedosporiosis due to L. proliferans has been described in immunocompromised patients, is typically due to rapid hematogenous dissemination, and is invariably fatal [55,59]. Most cases in immunocompetent hosts are due to direct inoculation (trauma or surgery). Diagnosis is made by direct observation of the mold in histology or recovery in sterile cultures (brain, CSF). Of note, L. proliferans may be recovered in blood cultures, which may facilitate the diagnosis. Non-cultural tests are non-specific and could be positive in patients with scedosporidiosis, supporting the diagnosis. Antifungal susceptibilities of Scedosporium apiospermum are variable. Voriconazole should be used as initial therapy while antifungal susceptibilities are pending. Although mortality is high in patients with disseminated infection, a voriconazole minimum inhibitory concentration (MIC) $<2 \mu \mathrm{g} / \mathrm{mL}$ has been associated with favorable outcomes [60]. L. proliferans, on the other hand, is resistant to all antifungal classes currently available. The combination of two antifungal agents has become a therapeutic alternative against $S$. apiospermum and L. proliferans [61-64]. In vitro studies have shown synergistic effects of voriconazole in combination with amphotericin B or echinocandins, against both S. apiospermum and L prolificans. An in vitro synergistic effect against $L$. prolificans has also been reported with terbinafine in combination with voriconazole, miconazole, or itraconazole $[65,66]$. Despite this promising in vitro data, the treatment of these infections is challenging, and outcomes are variable. Adjunctive surgical debridement and reversal of immunosuppression should be pursued when possible.

Funding: This work received no external funding.

Conflicts of Interest: Marisa H. Miceli is a consultant for Astellas and Scynexis.

\section{References}

1. Patterson, T.F.; Thompson, G.R., 3rd; Denning, D.W.; Fishman, J.A.; Hadley, S.; Herbrecht, R.; Kontoyiannis, D.P.; Marr, K.A.; Morrison, V.A.; Nguyen, M.H.; et al. Practice Guidelines for the Diagnosis and Management of Aspergillosis: 2016 Update by the Infectious Diseases Society of America. Clin. Infect. Dis. 2016, 63, e1-e60. [CrossRef] [PubMed]

2. Zanganeh, E.; Zarrinfar, H.; Rezaeetalab, F.; Fata, A.; Tohidi, M.; Najafzadeh, M.J.; Alizadeh, M.; Seyedmousavi, S. Predominance of non-fumigatus Aspergillus species among patients suspected to pulmonary aspergillosis in a tropical and subtropical region of the Middle East. Microb. Pathog. 2018, 116, 296-300. [CrossRef] [PubMed]

3. Lionakis, M.S.; Lewis, R.E.; Torres, H.A.; Albert, N.D.; Raad, I.I.; Kontoyiannis, D.P. Increased frequency of non-fumigatus Aspergillus species in amphotericin B or triazole-pre-exposed cancer patients with positive cultures for aspergilli. Diagn. Microbiol. Infect. Dis. 2005, 52, 15-20. [CrossRef] [PubMed]

4. Candoni, A.; Klimko, N.; Busca, A.; Di Blasi, R.; Shadrivova, O.; Cesaro, S.; Zannier, M.E.; Verga, L.; Forghieri, F.; Calore, E.; et al. Fungal infections of the central nervous system and paranasal sinuses in onco-haematologic patients. Epidemiological study reporting the diagnostic-therapeutic approach and outcome in 89 cases. Mycoses 2019, 62, 252-260. [CrossRef]

5. Pasqualotto, A.C.; Denning, D.W. Post-operative aspergillosis. Clin. Microbiol. Infect. 2006, 12, $1060-1076$. [CrossRef] [PubMed]

6. Jensen, J.; Guinea, J.; Torres-Narbona, M.; Muñoz, P.; Peláez, T.; Bouza, E. Post-surgical invasive aspergillosis: An uncommon and under-appreciated entity. J. Infect. 2010, 60, 162-167. [CrossRef] [PubMed]

7. Gonzales Zamora, J.A.; Henry, Z.; Gultekin, S.H. Central Nervous System Aspergillosis: An Unexpected Complication following Neurosurgery. Diseases 2018, 6, 46. [CrossRef]

8. $\quad$ Lewis, R.E.; Wiederhold, N.P.; Chi, J.; Han, X.Y.; Komanduri, K.V.; Kontoyiannis, D.P.; Prince, R.A. Detection of gliotoxin in experimental and human aspergillosis. Infect. Immun. 2005, 73, 635-637. [CrossRef] 
9. Lewis, R.E.; Wiederhold, N.P.; Lionakis, M.S.; Prince, R.A.; Kontoyiannis, D.P. Frequency and species distribution of gliotoxin-producing Aspergillus isolates recovered from patients at a tertiary-care cancer center. J. Clin. Microbiol. 2005, 43, 6120-6122. [CrossRef]

10. Eichner, R.D.; Al Salami, M.; Wood, P.R.; Müllbacher, A. The effect of gliotoxin upon macrophage function. Int. J. Immunopharmacol. 1986, 8, 789-797. [CrossRef]

11. Murayama, T.; Amitani, R.; Ikegami, Y.; Nawada, R.; Lee, W.J.; Kuze, F. Suppressive effects of Aspergillus fumigatus culture filtrates on human alveolar macrophages and polymorphonuclear leucocytes. Eur. Respir. J. 1996, 9, 293-300. [CrossRef] [PubMed]

12. Patel, R.; Hossain, M.A.; German, N.; Al-Ahmad, A.J. Gliotoxin penetrates and impairs the integrity of the human blood-brain barrier in vitro. Mycotoxin Res. 2018, 34, 257-268. [CrossRef] [PubMed]

13. Economides, M.P.; Ballester, L.Y.; Kumar, V.A.; Jiang, Y.; Tarrand, J.; Prieto, V.; Torres, H.A.; Kontoyiannis, D.P. Invasive mold infections of the central nervous system in patients with hematologic cancer or stem cell transplantation (2000-2016): Uncommon, with improved survival but still deadly often. J. Infect. 2017, 75, 572-580. [CrossRef] [PubMed]

14. Nadkarni, T.; Goel, A. Aspergilloma of the brain: An overview. J. Postgrad. Med. 2005, 51 (Suppl. 1), S37-S41.

15. Kourkoumpetis, T.K.; Desalermos, A.; Muhammed, M.; Mylonakis, E. Central nervous system aspergillosis: A series of 14 cases from a general hospital and review of 123 cases from the literature. Medicine 2012, 91, 328-336. [CrossRef]

16. Finelli, P.F.; Gleeson, E.; Ciesielski, T.; Uphoff, D.F. Diagnostic role of target lesion on diffusion-weighted imaging: A case of cerebral aspergillosis and review of the literature. Neurologist 2010, 16, 364-367. [CrossRef] [PubMed]

17. Boes, B.; Bashir, R.; Boes, C.; Hahn, F.; McConnell, J.R.; McComb, R. Central nervous system aspergillosis. Analysis of 26 patients. J. Neuroimaging 1994, 4, 123-129. [CrossRef]

18. Starkey, J.; Moritani, T.; Kirby, P. MRI of CNS fungal infections: Review of aspergillosis to histoplasmosis and everything in between. Clin. Neuroradiol. 2014, 24, 217-230. [CrossRef]

19. Corti, M.; Metta, H.; Villafañe, M.F.; Yampolsky, C.; Schtirbu, R.; Sevlever, G.; Garrido, D. Stereotactic brain biopsy in the diagnosis of focal brain lesions in AIDS. Medicina (B Aires) 2008, 68, 285-290.

20. Miceli, M.H.; Maertens, J. Role of Non-Culture-Based Tests, with an Emphasis on Galactomannan Testing for the Diagnosis of Invasive Aspergillosis. Semin. Respir. Crit. Care Med. 2015, 36, 650-661.

21. Reinwald, M.; Buchheidt, D.; Hummel, M.; Duerken, M.; Bertz, H.; Schwerdtfeger, R.; Reuter, S.; Kiehl, M.G.; Barreto-Miranda, M.; Hofmann, W.K.; et al. Diagnostic performance of an Aspergillus-specific nested PCR assay in cerebrospinal fluid samples of immunocompromised patients for detection of central nervous system aspergillosis. PLoS ONE 2013, 8, e56706. [CrossRef] [PubMed]

22. Imbert, S.; Brossas, J.Y.; Palous, M.; Joly, I.; Meyer, I.; Fekkar, A. Performance of Aspergillus PCR in cerebrospinal fluid for the diagnosis of cerebral aspergillosis. Clin. Microbiol. Infect. 2017, 23, 889.e1-889.e4. [CrossRef] [PubMed]

23. Chong, G.M.; Maertens, J.A.; Lagrou, K.; Driessen, G.J.; Cornelissen, J.J.; Rijnders, B.J. Diagnostic Performance of Galactomannan Antigen Testing in Cerebrospinal Fluid. J. Clin. Microbiol. 2016, 54, 428-431. [CrossRef] [PubMed]

24. Lyons, J.L.; Thakur, K.T.; Lee, R.; Watkins, T.; Pardo, C.A.; Carson, K.A.; Markley, B.; Finkelman, M.A.; Marr, K.A.; Roos, K.L.; et al. Utility of measuring (1,3)- $\beta$-d-glucan in cerebrospinal fluid for diagnosis of fungal central nervous system infection. J. Clin. Microbiol. 2015, 53, 319-322. [CrossRef] [PubMed]

25. Salvatore, C.M.; Chen, T.K.; Toussi, S.S.; DeLaMora, P.; Petraitiene, R.; Finkelman, M.A.; Walsh, T.J. $(1 \rightarrow 3)-\beta$-d-Glucan in Cerebrospinal Fluid as a Biomarker for Candida and Aspergillus Infections of the Central Nervous System in Pediatric Patients. J. Pediatr. Infect. Dis. Soc. 2016, 5, 277-286. [CrossRef] [PubMed]

26. Schwartz, S.; Ruhnke, M.; Ribaud, P.; Corey, L.; Driscoll, T.; Cornely, O.A.; Schuler, U.; Lutsar, I.; Troke, P.; Thiel, E. Improved outcome in central nervous system aspergillosis, using voriconazole treatment. Blood 2005, 106, 2641-2645. [CrossRef] [PubMed]

27. Schwartz, S.; Thiel, E. Cerebral aspergillosis: Tissue penetration is the key. Med. Mycol. 2009, 47 (Suppl. 1), S387-S393. [CrossRef]

28. Miceli, M.H.; Chandrasekar, P. Safety and efficacy of liposomal amphotericin B for the empirical therapy of invasive fungal infections in immunocompromised patients. Infect. Drug Resist. 2012, 5, 9-16. [PubMed]

29. Ng, A.; Gadong, N.; Kelsey, A.; Denning, D.W.; Leggate, J.; Eden, O.B. Successful treatment of aspergillus brain abscess in a child with acute lymphoblastic leukemia. Pediatr. Hematol. Oncol. 2000, 17, 497-504. [CrossRef] [PubMed] 
30. Khoury, H.; Adkins, D.; Miller, G.; Goodnough, L.; Brown, R.; DiPersio, J. Resolution of invasive central nervous system aspergillosis in a transplant recipient. Bone Marrow Transplant. 1997, 20, 179-180. [CrossRef]

31. Coleman, J.M.; Hogg, G.G.; Rosenfeld, J.V.; Waters, K.D. Invasive central nervous system aspergillosis: Cure with liposomal amphotericin B, itraconazole, and radical surgery—case report and review of the literature. Neurosurgery 1995, 36, 858-863. [CrossRef] [PubMed]

32. Herbrecht, R.; Denning, D.W.; Patterson, T.F.; Bennett, J.E.; Greene, R.E.; Oestmann, J.W.; Kern, W.V.; Marr, K.A.; Ribaud, P.; Lortholary, O.; et al. Voriconazole versus amphotericin B for primary therapy of invasive aspergillosis. N. Engl. J. Med. 2002, 347, 408-415. [CrossRef] [PubMed]

33. Denning, D.W.; Ribaud, P.; Milpied, N.; Caillot, D.; Herbrecht, R.; Thiel, E.; Haas, A.; Ruhnke, M.; Lode, H. Efficacy and safety of voriconazole in the treatment of acute invasive aspergillosis. Clin. Infect. Dis. 2002, 34, 563-571. [CrossRef] [PubMed]

34. Lee, A.; Prideaux, B.; Lee, M.H.; Zimmerman, M.; Dolgov, E.; Perlin, D.S.; Zhao, Y. Tissue Distribution and Penetration of Isavuconazole at the Site of Infection in Experimental Invasive Aspergillosis in Mice with Underlying Chronic Granulomatous Disease. Antimicrob. Agents Chemother. 2019, 63, e00524-19. [CrossRef] [PubMed]

35. Ullmann, A.J.; Aguado, J.M.; Arikan-Akdagli, S.; Denning, D.W.; Groll, A.H.; Lagrou, K.; Lass-Flörl, C.; Lewis, R.E.; Munoz, P.; Verweij, P.E.; et al. Diagnosis and management of Aspergillus diseases: Executive summary of the 2017 ESCMID-ECMM-ERS guideline. Clin. Microbiol. Infect. 2018, 24 (Suppl. 1), e1-e38. [CrossRef] [PubMed]

36. Dolton, M.J.; Ray, J.E.; Chen, S.C.; Ng, K.; Pont, L.G.; McLachlan, A.J. Multicenter study of voriconazole pharmacokinetics and therapeutic drug monitoring. Antimicrob. Agents Chemother. 2012, 56, 4793-4799. [CrossRef] [PubMed]

37. Andes, D.; Pascual, A.; Marchetti, O. Antifungal therapeutic drug monitoring: Established and emerging indications. Antimicrob. Agents Chemother. 2009, 53, 24-34. [CrossRef] [PubMed]

38. Schwartz, S.; Reisman, A.; Troke, P.F. The efficacy of voriconazole in the treatment of 192 fungal central nervous system infections: A retrospective analysis. Infection 2011, 39, 201-210. [CrossRef]

39. Walsh, T.J.; Raad, I.; Patterson, T.F.; Chandrasekar, P.; Donowitz, G.R.; Graybill, R.; Greene, R.E.; Hachem, R.; Hadley, S.; Herbrecht, R.; et al. Treatment of invasive aspergillosis with posaconazole in patients who are refractory to or intolerant of conventional therapy: An externally controlled trial. Clin. Infect. Dis. 2007, 44, 2-12. [CrossRef]

40. Pitisuttithum, P.; Negroni, R.; Graybill, J.R.; Bustamante, B.; Pappas, P.; Chapman, S.; Hare, R.S.; Hardalo, C.J. Activity of posaconazole in the treatment of central nervous system fungal infections. J. Antimicrob. Chemother. 2005, 56, 745-755. [CrossRef]

41. Imai, T.; Yamamoto, T.; Tanaka, S.; Kashiwagi, M.; Chiba, S.; Matsumoto, H.; Uede, T. Successful treatment of cerebral aspergillosis with a high oral dose of itraconazole after excisional surgery. Intern. Med. 1999, 38, 829-832. [CrossRef] [PubMed]

42. Maertens, J.; Raad, I.; Petrikkos, G.; Boogaerts, M.; Selleslag, D.; Petersen, F.B.; Sable, C.A.; Kartsonis, N.A.; Ngai, A.; Taylor, A.; et al. Efficacy and safety of caspofungin for treatment of invasive aspergillosis in patients refractory to or intolerant of conventional antifungal therapy. Clin. Infect. Dis. 2004, 39, 1563-1571. [CrossRef] [PubMed]

43. Okugawa, S.; Ota, Y.; Tatsuno, K.; Tsukada, K.; Kishino, S.; Koike, K. A case of invasive central nervous system aspergillosis treated with micafungin with monitoring of micafungin concentrations in the cerebrospinal fluid. Scand. J. Infect. Dis. 2007, 39, 344-346. [CrossRef] [PubMed]

44. Guest, J.M.; Singh, P.K.; Revankar, S.G.; Chandrasekar, P.H.; Kumar, A. Isavuconazole for Treatment of Experimental Fungal Endophthalmitis Caused by Aspergillus fumigatus. Antimicrob. Agents Chemother. 2018, 62, e01537-18. [CrossRef] [PubMed]

45. De Leonardis, F.; Novielli, C.; Giannico, B.; Mariggiò, M.A.; Castagnola, E.; Santoro, N. Isavuconazole Treatment of Cerebral and Pulmonary Aspergillosis in a Pediatric Patient with Acute Lymphoblastic Leukemia: Case Report and Review of Literature. J. Pediatr. Hematol. Oncol. 2019. [CrossRef]

46. Stevens, D.A.; Shatsky, S.A. Intrathecal amphotericin in the management of coccidioidal meningitis. Semin. Respir. Infect. 2001, 16, 263-269. [CrossRef]

47. Peterson, A.; Pham, M.H.; Lee, B.; Commins, D.; Cadden, J.; Giannotta, S.L.; Zada, G. Intracranial fusarium fungal abscess in an immunocompetent patient: Case report and review of the literature. J. Neurol. Surg. Rep. 2014, 75, e241-e245. 
48. Garcia, R.R.; Min, Z.; Narasimhan, S.; Bhanot, N. Fusarium brain abscess: Case report and literature review. Mycoses 2015, 58, 22-26. [CrossRef]

49. Kleinschmidt-Demasters, B.K. Disseminated Fusarium infection with brain abscesses in a lung transplant recipient. Clin. Neuropathol. 2009, 28, 417-421. [CrossRef]

50. Dignani, M.C.; Anaissie, E. Human fusariosis. Clin. Microbiol. Infect. 2004, 10 (Suppl. 1), 67-75. [CrossRef]

51. Koutsouras, G.W.; Ramos, R.L.; Martinez, L.R. Role of microglia in fungal infections of the central nervous system. Virulence 2017, 8, 705-718. [CrossRef] [PubMed]

52. Nucci, F.; Nouér, S.A.; Capone, D.; Anaissie, E.; Nucci, M. Fusariosis. Semin. Respir. Crit. Care Med. 2015, 36, 706-714. [CrossRef] [PubMed]

53. Bertero, A.; Spicer, L.J.; Caloni, F. Fusarium mycotoxins and in vitro species-specific approach with porcine intestinal and brain in vitro barriers: A review. Food Chem. Toxicol. 2018, 121, 666-675. [CrossRef] [PubMed]

54. Góralska, K.; Blaszkowska, J.; Dzikowiec, M. Neuroinfections caused by fungi. Infection 2018, 46, 443-459. [CrossRef] [PubMed]

55. McCarthy, M.; Rosengart, A.; Schuetz, A.N.; Kontoyiannis, D.P.; Walsh, T.J. Mold infections of the central nervous system. N. Engl. J. Med. 2014, 371, 150-160. [CrossRef] [PubMed]

56. Nesky, M.A.; McDougal, E.C.; Peacock, J.E., Jr. Pseudallescheria boydii brain abscess successfully treated with voriconazole and surgical drainage: Case report and literature review of central nervous system pseudallescheriasis. Clin. Infect. Dis. 2000, 31, 673-677. [CrossRef]

57. Signore, S.C.; Dohm, C.P.; Schütze, G.; Bähr, M.; Kermer, P. Scedosporium apiospermum brain abscesses in a patient after near-drowning-A case report with 10-year follow-up and a review of the literature. Med. Mycol. Case Rep. 2017, 17, 17-19. [CrossRef]

58. Lee, M.G.; Choi, J.G.; Son, B.C. Scedosporium apiospermum: An Emerging Fatal Cause of Fungal Abscess and Ventriculitis after Near-drowning. Asian J. Neurosurg. 2018, 13, 792-796.

59. Marco de Lucas, E.; Sádaba, P.; Lastra García-Barón, P.; Ruiz Delgado, M.L.; Cuevas, J.; Salesa, R.; Bermúdez, A.; González Mandly, A.; Gutiérrez, A.; Fernández, F.; et al. Cerebral scedosporiosis: An emerging fungal infection in severe neutropenic patients: CT features and CT pathologic correlation. Eur. Radiol. 2006, 16, 496-502. [CrossRef]

60. Martin-Vicente, A.; Guarro, J.; González, G.M.; Lass-Flörl, C.; Lackner, M.; Capilla, J. Voriconazole MICs are predictive for the outcome of experimental disseminated scedosporiosis. J. Antimicrob. Chemother. 2017, 72, 1118-1122. [CrossRef]

61. Bhat, S.V.; Paterson, D.L.; Rinaldi, M.G.; Veldkamp, P.J. Scedosporium prolificans brain abscess in a patient with chronic granulomatous disease: Successful combination therapy with voriconazole and terbinafine. Scand. J. Infect. Dis. 2007, 39, 87-90. [CrossRef] [PubMed]

62. Meletiadis, J.; Mouton, J.W.; Meis, J.F.; Verweij, P.E. In vitro drug interaction modeling of combinations of azoles with terbinafine against clinical Scedosporium prolificans isolates. Antimicrob. Agents Chemother. 2003, 47, 106-117. [CrossRef] [PubMed]

63. Singh, R.P.; McCluskey, P. Scedosporium prolificans sclerokeratitis 10 years after pterygium excision with adjunctive mitomycin C. Clin. Exp. Ophthalmol. 2005, 33, 433-434. [CrossRef] [PubMed]

64. Howden, B.P.; Slavin, M.A.; Schwarer, A.P.; Mijch, A.M. Successful control of disseminated Scedosporium prolificans infection with a combination of voriconazole and terbinafine. Eur. J. Clin. Microbiol. Infect. Dis. 2003, 22, 111-113. [PubMed]

65. Cuenca-Estrella, M.; Alastruey-Izquierdo, A.; Alcazar-Fuoli, L.; Bernal-Martinez, L.; Gomez-Lopez, A.; Buitrago, M.J.; Mellado, E.; Rodriguez-Tudela, J.L. In vitro activities of 35 double combinations of antifungal agents against Scedosporium apiospermum and Scedosporium prolificans. Antimicrob. Agents Chemother. 2008, 52, 1136-1139. [CrossRef] [PubMed]

66. Yustes, C.; Guarro, J. In vitro synergistic interaction between amphotericin B and micafungin against Scedosporium spp. Antimicrob. Agents Chemother. 2005, 49, 3498-3500. [CrossRef]

(C) 2019 by the author. Licensee MDPI, Basel, Switzerland. This article is an open access article distributed under the terms and conditions of the Creative Commons Attribution (CC BY) license (http://creativecommons.org/licenses/by/4.0/). 